\title{
A ARTE SANTEIRA NO E DO PIAUÍ
}

Daniel Oliveira da Silva

Fabiano Gontijo

As técnicas corporais da produção de santos talhados em madeira no Piauí, arte santeira, que ligam o gesto aos instrumentos, foram tomadas como narrativas da identidade piauiense em pesquisa realizada entre 2006 e 2008, com o intuito de contribuir para a definição da cidadania cultural no Piauí. [Abstract on page 243]

ARTE SANTEIRA, TÉCNICAS CORPORAIS, PIAUÍ. 


\section{APRESENTAÇÃO ${ }^{l}$}

A importância da arte santeira piauiense é definida pela renomada produção de artefatos de madeira esculpidos ou talhados por escultores oriundos das camadas populares do estado. A criatividade de homens e mulheres em dotar a madeira de formas com

1 Este trabalho teve início no âmbito do Programa de Especialização em Patrimônio, Iphan/Unesco, entre 2006 e 2008; contou também com recursos de uma bolsa de produtividade em pesquisa do CNPq. temáticas religiosas fez surgir o ofício de santeiro, designação dada aos detentores do saber tradicional fundamental para a confecção desses artefatos.

Trata-se aqui de identificar o papel dos atores sociais que detêm o conhecimento das técnicas e matérias-primas utilizadas nessa produção direta ou indiretamente vinculada ao domínio do cristianismo e que inclui santos, anjos, oratórios, entalhes, figuras regionais e ex-votos. A arte santeira é considerada pelos poderes públicos bem de inestimável valor cultural para a formação da identidade da população piauiense.

Processo desenvolvido ao longo da história da gestão do patrimônio cultural no Brasil, os debates teóricos desembocaram, nos últimos anos, numa abordagem multidisciplinar - a partir das artes, da história e da antropologia - para enfrentar a dicotomia arte culta ou erudita e arte popular. Sem adentrar os parâmetros que regem os conceitos definidores da concepção de arte, vale destacar que a inserção, no século XX, da moderna concepção antropológica de cultura serviu para atenuar determinadas questões. Isso porque, segundo essa nova definição, cultura significa que "a ênfase está nas relações sociais ou mesmo nas relações simbólicas, e não nos objetos e nas técnicas" (GONÇALVES, 2003: 27). Dessa forma, foi possível trazer o conceito antropológico de cultura para dentro das categorias que definem o patrimônio, permitindo estender sua abrangência ao universo do fazer e do existir tradicionais contidos nas expressões populares.

A partir dos anos 70 foi possível conceber a cultura popular como parte integrante do contexto de transformações em andamento na sociedade como um todo. Percebe-se, aí, o sempre presente aproximar e acompanhar das revoluções tecnológicas trazidas pela modernidade e que funcionariam como articuladores das identidades para esses segmentos sociais populares - como os que produzem a arte santeira -, sem obstruir a consonância direta com suas raízes culturais, estratégia utilizada para favorecer sua permanência na dinâmica usual da complexidade social, revelando, assim, seu caráter contemporâneo que a todo momento inventa e reinventa a tradição. Como observa Cavalcanti,

A cultura popular interpreta as noções de tradicional e moderno dentro de seu próprio universo de relações. Estabelece, assim, distinções internas, nunca absolutas ou imutáveis, que buscam controlar e refletir sobre mudanças sociais em curso, com as quais inevitavelmente se depara (CAVALCANTI, 2001: 75).

A identidade nacional seria, então, uma combinação de elementos ordenados pelas diversas regionalidades existentes no território brasileiro. Ao assumir essa nova posição, a política de proteção do patrimônio cultural nacional adota viés pluralista para sua 
ação, permitindo, assim, o reconhecimento de determinados valores que adornam os elementos identitários no processo de formação da sociedade brasileira.

Importantes reflexos foram gerados, como o contido no artigo 216 da Constituição Federal de 1988, que determinou as responsabilidades do "poder público, com a colaboração da comunidade", na promoção e proteção do patrimônio cultural brasileiro, compreendido como os “(...) bens de natureza material e imaterial, tomados individualmente ou em conjunto, portadores de referência à identidade, à ação, à memória dos diferentes grupos formadores da sociedade brasileira" (BRASIL, 1988). A interpretação desse trecho da carta magna instaura, de modo explícito, novo campo de atuação política concentrado nas expressões culturais de toda ordem, servindo, então, de norte para a fundamentação de futuras soluções nas ações de preservação patrimonial no país.

A promulgação do Decreto 3.551/00 definiu quatro categorias, cada qual com seu livro correspondente no Iphan, para os bens culturais imateriais ou intangíveis que estruturarão o processo de registro, quais sejam: os saberes, as celebrações, as formas de expressão e os lugares. No caso da arte santeira piauiense, seu registro se poderia enquadrar na categoria saberes, devido à natureza de sua dinâmica em conjeturar ambiente de transmissão, às novas gerações, do "saber fazer" não evidenciado no resultado material do artefato produzido; isto porque a etapa precedente, ou seja, o imaterial ou intangível, corresponderia a determinada leva de procedimentos, técnicas e formas de organização do trabalho e da produção, orquestrada por aspectos simbólico-culturais característicos do grupo social - no caso, os santeiros.

Adentrar o universo dos santeiros tentando desvendar fielmente suas experiências no desígnio de sua arte é o objetivo central deste estudo. Contando com isso, recorremos às lentes da antropologia e da sociologia para auxiliar na decodificação dos signos que configuram o saber e o fazer embutidos no ofício de quem produz arte santeira no Piauí.

O caminho a ser percorrido inclui pesados troncos de madeira, uma variedade de ferramentas de diferentes tamanhos e oferecendo múltiplos riscos, uma diversidade de artefatos representando o sagrado em muitas formas e dimensões, e ele, o santeiro, concentrando-se nos cortes que darão a forma a madeira - embora fisicamente presente, pergunto-me onde andará, naquele momento, sua mente, que logo trará ao cenário mais um personagem esculpido para encantar não só aquele espaço, mas um universo mais abrangente.

\section{A ARTE SANTEIRA}

No Piauí, a produção da imaginária sacra aborda predominantemente a representação do universo da religiosidade católica. A madeira é a matéria-prima utilizada pelos chamados santeiros para esculpir e talhar as formas de santos, anjos, oratórios, entaIhes, figuras regionais e ex-votos. A utilidade desses artefatos revela múltiplas possibilidades nos dias de hoje, podendo ocupar espaços em feiras de artes e artesanato, integrar o acervo de museus de arte sacra e igrejas, ser meio de pagamento de promessas nas ro- 
marias a santuários sagrados ou mesmo servir como elemento de decoração, referenciando certo consumo da produção artística regional.

Pelo porte que foi adquirindo ao longo dos anos no cenário cultural piauiense, essa manifestação artística é conhecida como "arte santeira do Piauí". Sua difusão deu-se a partir da relevância que as obras de Mestre Dezinho, abrigadas na Igreja Nossa Senhora

2 A igreja, situada no Bairro da Vermelha, em Teresina, foi alvo do estudo que embasou a proposta de ação preservacionista realizado por Ivana Medeiros Pacheco Cavalcante (Iphan). Nesse estudo, ela propõe o tombamento federal do edificio e dos bens integrados que compõem o templo, de propriedade da paróquia de mesmo nome. de Lourdes², alcançaram no cenário das artes populares. Essa tradição conseguiu atrair a atenção de apreciadores, colecionadores e estudiosos de arte que, a princípio, atrelaram aos artefatos o valor de "arte" e de "popular", depois do que o santeiro passou a ser conhecido como artista da cultura popular. Segundo Mesquita,

Dezinho foi o descortinar de múltiplas possibilidades de valorização de arte popular. A partir do momento em que uma igreja paroquial recém-construída admitiu ser ocupada por santos, anjos e entalhes de nítida origem e expressões populares (MESQUITA, 1980: 13).

Essa circunstância, reveladora do talento e da criatividade genuína de Mestre Dezinho, posterior à construção da igreja, por volta de 1970, foi o suficiente para que se tomasse conhecimento da existência de diversos santeiros habilidosos espalhados por todo o Piauí, entre eles Mestre Expedito, que também possui peças compondo o acervo da referida igreja, constituindo legado de obras de arte que se encontra em situação de carência de ações preservacionistas. Segundo Girão, é "através da arte que (...) os homens manifestam ideias em produtos sensíveis que constituem um legado (...) ao mesmo tempo permanente e contínuo para a humanidade. Tal legado forma um elenco de patrimônio cultural também permanente e contínuo" (GIRÃO, 2001). A integração das imagens à composição arquitetônica atraiu a atenção da comunidade local, bem como de apreciadores e interessados em arte. A igreja, então, passou a ser ponto de visitação de turistas, bem como bastante requisitada para celebrações de ritos católicos. Segundo Fischer

toda arte é condicionada pelo seu tempo e representa a humanidade em consonância com as ideias e aspirações, as necessidades e as esperanças de uma situação histórica particular. Mas, ao mesmo tempo, a arte supera essa limitação e, de dentro do momento histórico, cria também um momento de humanidade que promete constância no desenvolvimento (FISCHER, 1967:18).

O retrato de um Brasil regional e pitoresco, sob a perspectiva do sertão, pode ser constatado nas formas empregadas na produção dos artefatos. O saber fazer da arte santeira piauiense caracteriza-se pela utilização de técnicas manuais e ferramentas rudimentares para reproduzir, na madeira, os traços que expressam a busca de inspiração, por parte do santeiro, no espaço social em que está inserido.

O Piauí é a própria imagem do sertão. Com predominância da vegetação de caatinga e do clima semiárido em seu território, e enfrentando meses de estiagem, configura o cenário em que a figura do vaqueiro, com sua veste de couro, atravessa a região 
inóspita no tanger do gado entre fazendas e pastagens. A esse ambiente acrescenta-se o conforto da fé que o homem sertanejo deposita na esperança de melhores condições de vida. No entanto, embora esse padrão cultural ainda possa ser detectado na realidade, ele está muito mais presente no imaginário social, consistindo em elemento significativo da construção da identidade cultural piauiense.

Em tal contexto, é importante salientar que o Piauí, com população estimada em quase três milhões de habitantes (IBGE: 2005), é o único estado do Nordeste em que a capital não está situada no litoral, conservando, assim, características próprias das culturas que se formatavam do sertão para o litoral. Segundo dados do Censo de 2000, confirmados por pesquisas recentes da Fundação Getúlio Vargas, o estado revelou deter a maior proporção de pessoas que se dizem católicas do Brasil (91,3\%). Logo, as dimensões alcançadas pela prática religiosa cotidiana estão presentes em diversos aspectos da vida social. Isso não poderia ser diferente no campo da imaginária, que ganha importante papel nesse quadro, devido à necessidade de satisfazer anseios espirituais da população.

Em sua maioria do sexo masculino, esses artesãos/artistas demonstram compartilhar experiências de vida semelhantes, tais como origem ou raízes rurais, baixa escolaridade e instabilidade financeira. É, entretanto, a capital, Teresina, que se consagra como celeiro, por excelência, desses renomados santeiros. Lá se concentra a maioria de artesãos/artistas do estado voltados para a arte sacra, constituindo importantíssimo polo de produção artesanal, que, ultrapassando as fronteiras da demanda local, garante seu lugar cativo no cenário das artes populares brasileiras e atrai a atenção internacional. $^{3}$

3 Mestre Dezinho teve obras expostas e premiadas em Milão e na Bienal de Arte Popular em Bratislava, em 1972; na mostra Brasil Export, em Bruxelas, em 1973; na Bienal Nacional de São Paulo, em 1974, entre outros eventos.

Seria possível pensar que a arte santeira piauiense constitui-se, então, como manifestação artística e cultural guardiã de alguns elementos que estão na base da própria "identidade nacional brasileira"?

\section{DEZINHO DE VALENÇA DO PIAUÍ}

Quando se fala em arte santeira piauiense, logo vêm à cabeça Mestre Dezinho e a Paróquia de Nossa Senhora de Lourdes, comumente chamada de Igreja da Vermelha. Um homem e um prédio, o artista e o templo. Essa foi a combinação original simbólica que deu impulso a um fenômeno artístico de grande valor cultural do Piauí, associado à atividade de colecionadores e artistas diversos que vinham pensando a identidade piauiense. As esculturas do Cristo no altar, dos santos e anjos feitos pelo mestre exclusivamente para compor o acervo litúrgico daquela estrutura, que mais parece um galpão de cargas, revelaram a marca profunda de elementos da cultura nordestina, ressignificados por quem os fez.

Nascido em Valença do Piauí em 1916, José Alves de Oliveira teve seu primeiro contato com a madeira aos 10 anos, por intermédio do pai, agricultor e carpinteiro, cuja morte Ihe ampliou responsabilidades. Foi servente de pedreiro e, em seguida, empregou- 
se em uma oficina de marcenaria para conhecer melhor os segredos da madeira na fabricação de implementos, como engenhos e fôrmas de rapadura, e móveis de estilo colonial. A devoção religiosa de Mestre Dezinho - que, segundo ele, herdou do pai - fazia-o atender aos pedidos de ex-votos dos penitentes que se dirigiam a São Francisco do Canindé, no Ceará, e a Santa Cruz dos Milagres, no Piauí, em caudalosas romarias.

Em 1961, mudou-se para Teresina em busca de melhores condições de vida para sua família. Tornou-se vigia noturno da Praça do Bairro Vermelha. Por volta de 1969, a Igreja de Nossa Senhora de Lourdes estava sendo erguida, e ali ele passou a trabalhar durante o dia como marceneiro na construção do prédio que, no turno da noite, vigia-

\begin{abstract}
4 Pintor teresinense, formado pela Escola Nacional de Belas Artes, em 1960. Produziu as telas que retratam a Paixão de Cristo exclusivamente para compor o acervo da Igreja Nossa Senhora de Lourdes. As molduras desses quadros foram talhadas por Mestre Expedito, fazendo parte, tal como as telas, da composição artística delimitada na categoria de bens integrados no processo de tombamento da igreja.
\end{abstract} va. Um dia foi surpreendido pelo pároco, padre Francisco das Chagas Carvalho, fazendo ex-votos no porão da igreja, como costumava fazer em sua cidade natal. Em outra ocasião, já com as paredes da igreja rebocadas, Mestre Dezinho foi convidado pelo padre, junto com Afrânio Castelo Branco, ${ }^{4}$ para fazer a imagem de Cristo crucificado que comporia o altar do templo. Naquele momento, humildemente declarou não ser capaz de realizar tal façanha, ou seja, 'juntar as peças', aludindo aos ex-votos que fazia. No dia seguinte, o padre mandou entregar-lhe uma tora de cedro de dois metros de comprimento. Instado pela insistência do pároco, Mestre Dezinho iniciou a escultura e teve bastante dificuldade para concluí-la. O resultado foi, ao contrário das expectativas do mestre, recebido com bastante entusiasmo. O sucesso foi de tal ordem, que o padre o requisitou novamente, dessa vez para esculpir as imagens de Nossa Senhora de Lourdes em aparição a Santa Bernadete e dos anjos tocheiros, além da mesa do altar, cujas laterais são ornadas com anjos em alto-relevo (SILVA, 1998).

É fato e por valor que a figura de Mestre Dezinho protagoniza a história da arte santeira do Piauí, e o palco dessa narrativa se instala no interior da Igreja Nossa Senhora de Lourdes. Esses dois fenômenos são os alicerces da constatação de que determinados bens e práticas passam a constituir um sistema referencial específico do contexto da manifestação em questão.

Portanto, a partir das referências culturais da arte santeira piauiense podemos dar início à compreensão do universo cultural de construção de sentidos que são constantemente ressignificados pelo grupo social em questão, caracterizando sua identidade. Esses significados determinam a dinâmica da realidade social e projetam as experiências vividas dos atores envolvidos em um processo de transmissão dos saberes culturais, através das técnicas corporais, para as novas gerações, do qual a arte santeira piauiense é bom exemplo. 


\section{AS “TÉCNICAS CORPORAIS" E O “PODER DISCIPLINAR”}

A arte santeira piauiense é manifestação cultural que demonstra determinado ofício e determinados modos de fazer manualmente elaborados por um grupo de "legítimos" representantes das artes populares, entre eles homens e mulheres, mestres e aprendizes que, no uso de suas atribuições, fazem o entrelaçamento de estética e outros domínios do pensamento. Essa prática é revestida por processo de formação identitária do grupo que tem agregado aos artefatos produzidos valores históricos e culturais. Segundo Gonçalves (2003), a arte enquanto prática deve ser pensada como construção discursiva e narrativa que pode justificar crenças e ideologias. É na análise interpretativa das "técnicas corporais" que podemos justificar as práticas de produção da arte santeira piauiense, com o intuito de caracterizar a própria identidade cultural, ou seja, a conjunção de prática e ideologias.

Em meio a posturas e valores que formularam a arte santeira do Piauí está a forte presença da religião católica que, aqui, condensa caracteres híbridos. Esse tipo de tradição católica está atrelado a conhecimentos enraizados no cotidiano e envolto por aspectos simbólicos próprios, determinados pela dinâmica total da realidade moral e social dos indivíduos, em função do meio físico e do caráter peculiar dos métodos de sociabilidades desenvolvidos na região.

Nesse sentido, a arte santeira piauiense parece se aplicar àquilo que Mauss (1974) denominou "fato social total", incluindo os diferentes aspectos que constroem a realidade, o econômico, o social, o político, o jurídico, o moral, o artístico (estético e morfológico), ou seja, toda a vida social ali misturada.

Um olhar sobre a produção da arte santeira piauiense conduz ao universo de alternativas e possibilidades permeadas pelas instituições sociais que trazem à tona trajetórias de vida e concepções de mundo de quem produz. O estudo dos elementos caracteriza uma forma de extrair o entendimento dos aspectos simbólicos e materiais que viabilizaram a formulação de um saber fazer eficaz para a permanência dessa manifestação artística.

Cabe aos santeiros a interlocução pela qual os componentes simbólicos ganham sua versão material nos traços que vão talhando a madeira até formar a escultura. 0 produto da cultura passa a representar o grupo de especialistas que reproduz a imaginária, configurando fenômeno que expressa a relação do homem com o meio, ou seja, o real em sua totalidade material, imaterial, natural e cultural, em suas dimensões de tempo e espaço; formando, enfim, um legado de patrimônio cultural.

O "fato social total" indica um caminho para o estudo do corpo capaz de apreender as possíveis relações de afinidade entre a sociedade e o homem. Culturalmente falando, o bem material consagra-se como a extensão do mundo simbólico e como condição para sua existência, sendo mediado pelo uso das "técnicas corporais". O corpo humano é modelado conforme os valores e significados de cada grupo social; isso quer dizer 
que qualquer experiência material, independente do estado tecnológico alcançado pelo grupo na transformação da natureza em cultura, prescinde da condição humana.

O corpo do artesão/artista é o foco da análise das técnicas e dos hábitos corporais, da produção de saberes e poder e dos aspectos disciplinares produzidos no corpo. Procurando considerar inicialmente o que afirma Mauss (1974: 217), “(...) o corpo é o primeiro e o mais natural instrumento do homem. Mais exatamente, sem falar de instrumento, o primeiro e mais natural objeto técnico, e ao mesmo tempo meio técnico do homem é seu corpo".

Mauss chama de técnicas corporais “(...) um ato tradicional eficaz (e vejam que, nisto, não difere do ato mágico, religioso, simbólico). É preciso que seja tradicional e eficaz. Não há técnica e tampouco transmissão se não há tradição". Por isso, torna-se santeiro aquele indivíduo que cria, ao longo da vida e em função de seu contexto cultural, certos costumes que se vão tornando tradicionais, sendo transmitidos por mestres a aprendizes. Esses procedimentos vão-se tornando tradicionais justamente porque são dotados de eficácia simbólica, ou seja, respondem a certas demandas da sociedade, adotando significados importantes para o grupo. Cada grupo social apresenta um comportamento especializado para o corpo na produção de códigos que determinam suas identidades. Na visão de Strozenberg,

cada cultura 'modela' ou 'fabrica' à sua maneira um corpo humano. Toda sociedade se preocupa em imprimir no corpo, fisicamente, determinadas informações, mediante as quais a cultura se inscreve e grava sobre o biológico; arranhando, rasgando, perfurando, queimando a pele, opõem-se nos corpos, cicatrizes-signos, que são formas artísticas ou indicadores rituais de posição social (...), práticas que se explicam por razões sempre sociais, de ordem social ou estética (STROZENBERG, 1986: 91).

No caso da arte santeira, são utilizados na fabricação de santos e ex-votos, a madeira e instrumentos manuais para talhá-la, como a faca, o serrote, o enxó, os formões e as goivas, entre outros. Mãos calejadas, dedos lascados e inúmeras cicatrizes são as marcas deixadas pela prática cotidiana do ofício e que podem servir como geradores de signos para o etnógrafo ou o sociógrafo em campo na identificação do grupo de artesãos/ artistas piauienses.

A experiência vivida na relação entre mestres e aprendizes da arte santeira piauiense indica um processo de transmissão do "saber fazer". O mestre repassa o conhecimento das técnicas de seu ofício para outro indivíduo, em geral bem mais jovem do que o mestre. A dedicação por parte do aprendiz em aperfeiçoar a estética do artefato, em adquirir respeito e reconhecimento vai determinar sua ascensão ao status de mestre. O conhecimento passa a ser entendido atrelado ao "poder", organizando uma forma hierarquizada de ação; segundo Foucault (1979), trata-se de um poder disciplinar que constrói o indivíduo através de saber que permite o controle do corpo (Machado, 1979). 


\section{OS SANTEIROS}

O espaço social de atuação dos santeiros acontece de norte a sul do estado, ainda que a maioria deles esteja concentrada na capital, Teresina, berço do reconhecimento dos trabalhos de Mestre Dezinho e Mestre Expedito.

A morte de Mestre Dezinho não decretou o fim da arte santeira piauiense enquanto produção; pelo contrário, estabeleceu-se um ciclo de "tradição contemporânea". Mestre Expedito assume, então, o posto de mais velho e principal santeiro em atividade no Piauí. Aspecto também relevante foi o emprego de aprendizes por parte de Mestre Dezinho, para ajudá-lo em algumas etapas da produção dos artefatos, o que determinou um processo de transmissão da maestria. Dos aprendizes, José Joaquim (Kim), Raimundo Lima (Dim), Costinha e Barradas permaneceram fiéis ao oficio e também são chamados de mestres.

Na narrativa dos santeiros é possível perceber a correspondência que estabelecem entre seu ofício e a figura de Mestre Dezinho. Para eles, essa é maior referência, motivo de admiração, respeito e até devoção.

Eu trabalhei com um dos maiores mestres do Piauí, que é Mestre Dezinho, e lembro dele com todo respeito (Mestre Dim).

(...) O Mestre Dezinho foi o pioneiro na arte santeira daqui do Piauí... e através dele, ele principalmente, foi quem abriu as portas do artesanato do Piauí, então ele foi o pioneiro (Mestre Kim).

(...) Eu tive muito com o véi Dezinho, ele contava muitas histórias para mim. A maior lição que ele me deixou foi... procurar trabalhar sempre e com a melhor perfeição. Mesmo que a peça seja vendida barata, mas nunca deixar de ter a qualidade (Costinha, que não se diz mestre).

A maioria dos santeiros recorre à memória de Mestre Dezinho para agregar valor mercadológico às peças que produz. Em sua interpretação, só com os santeiros piauienses é possível adquirir uma escultura que assuma a memória do grande mestre, consolidando uma forma de diferenciação da arte sacra produzida em outros estados e sublinhando aspectos que tornam aquele grupo único, distinto dos demais, compartilhado por todos como se a eles individualmente pertencessem.

Embora se digam católicos, praticantes ou não, pode-se considerar que a arte santeira piauiense, hoje, é atividade econômica que responde às necessidades de sobrevivência dos santeiros e de suas famílias. Isso, entretanto, não compromete a produção, talvez por devoção - ou, quiçá, busca de redenção -, de um artefato religioso no sentido votivo, que pode não acarretar nenhum ou quase nenhum ônus para quem o encomendou.

Em geral é na produção de ex-votos que o sentido votivo está majoritariamente embutido no artefato. $\mathrm{O}$ ex-voto é usado em práticas mágico-religiosas, ofertados a divindades, particularmente aos santos, em retribuição a graças ou benefícios recebidos. São, portanto, representações materiais com as quais os devotos cumprem suas promessas. A precária condição de vida e a devoção são características de quem faz uso do ex-voto 
e delega, assim, o sanar de suas mazelas e seus sofrimentos às entidades sobrenaturais. Portanto, os ex-votos podem ser considerados representação de “(...) necessidades individuais que podem se converter em problemas sociais" (GIFFONI, 1980: 29). Ao tomar conhecimento da situação em que se encontra o devoto, o santeiro, muitas vezes, se abstém de cobrar pela produção do ex-voto ou pede apenas pequena quantia pelo pedaço de madeira utilizada - mas não assina a obra...

A utilização da arte santeira piauiense no sentido votivo prossegue com as demandas de cristos, santos e anjos advindas de igrejas, capelas, oratórios particulares. Assim como aconteceu com a Paróquia de Nossa Senhora de Lourdes, muitas igrejas, tanto na capital como no interior, estão adquirindo imagens talhadas por santeiros do próprio Piauí.

Outra ocorrência frequente - que pudemos constatar em campo - é o emprego dos santeiros na restauração de peças sacras antigas abrigadas em igrejas históricas do Piauí, que também já incluem obras dos mestres Dezinho e Expedito. Bom exemplo é a proposta de restauração das obras de Mestre Dezinho que estão bastante mutiladas, mais devido à ação do homem do que do tempo; a intervenção nas obras é contrapartida do próprio pároco, que propõe confiar o trabalho às mãos do genro e sobrinho do autor das obras, Mestre Kim.

Para além da sacralização do objeto, a vasta produção da arte santeira piauiense revela usos diferenciados ao destinar grande parte das esculturas a um público cativo que lhes dá a função de suvenires ou totens. Essa demanda é atraída pela produção artística do artefato, que é percebido como regional e pitoresco, e passa a ser utilizado como objeto de decoração. Hoje em dia, essa tendência é responsável por grande parte da divulgação, apreciação e comercialização das esculturas e entalhes feitos por santeiros piauienses em salões e mostras de arte e artesanato no Brasil e em outros países.

Os usos diferenciados da arte santeira piauiense não devem ser pensados na forma da demarcação de confronto entre aspectos tradicionais e contemporâneos. Na análise dos processos culturais não se pode abdicar da dinâmica de sua natureza. Portanto, a tentativa de aprisionar no tempo um dado bem cultural pode acarretar efeito contrário ao de se tentar manter intocada genuinidade, e o bem pode vir a perder-se. É preciso antes interpretar os fatos como inseridos em um contexto cultural contemporâneo, constituído de pessoas e grupos sociais que vivem e atuam em um ambiente de transformações. A interação entre esses aspectos cognitivos vem contribuindo para dar maior visibilidade à arte santeira piauiense e reforço na construção da identidade cultural estadual.

Ao observar os santeiros piauienses é possível visualizar uma postura nesse sentido. A própria estrutura montada para realização da atividade mescla elementos de diferentes épocas, ou seja, pode-se afirmar que o antigo e o novo formam um sistema de práticas que movimenta a arte santeira piauiense - isso se evidencia na utilização de ferramentas rudimentares para esculpir a peça, paralela ao uso que o mestre faz de celular para comercializar seus produtos... 
Voltando à fabricação do artefato, é recorrente também a utilização de ferramentas modernas, como a furadeira elétrica. Essa e outras novas adaptações são empregadas com o objetivo fundamental de reduzir tanto o tempo de produção da peça, quanto o desgaste do corpo do santeiro. Esses procedimentos acabam exigindo conhecimento especializado para sua aplicação; portanto, é necessário recorrer ao uso das técnicas corporais que foram moldadas para aquela finalidade específica.

A educação de um corpo especializado é pré-requisito indispensável para a dinâmica da produção da arte santeira piauiense. Nesse quadro, consideramos que a construção de determinado tipo de conhecimento passa pela definição de uma ordem hierárquica de poder, o poder disciplinar, que está nitidamente presente na relação mestre/ aprendiz.

Entrevistas realizadas com os mestres Kim, Dim e Costinha, que foram aprendizes de Mestre Dezinho, apontam para o fato de sua formação na arte de esculpir madeira se dever às orientações passadas por seu mestre. Às vezes, passavam mais horas na oficina do que em casa. Portanto, o ambiente de uma oficina de santeiros reproduz a estrutura familiar, o poder paterno se configurando na pessoa do mestre que instrui seus jovens pupilos quanto à direção da vida.

Das experiências nesse sentido é importante destacar o exemplo de Kim, que, além de pertencer à terceira geração de artesãos ${ }^{5}$ da família, foi preparado por seu tio e sogro, Dezinho, para sucedê-lo no ofício de santeiro. Quando criança, Kim fazia miniaturas em giz e em grafite; ao tomar conhecimento dessa atividade, Dezi5 O avô de Kim, pai de Mestre Dezinho, trabaIhou com madeira na produção de engenhos e móveis em estilo colonial. nho convidou-o para sua oficina no intuito de aperfeiçoar o trabaIho. Kim se denomina o discípulo sucessor de Mestre Dezinho: "Ele me preparou para dar continuidade ao trabalho dele. Desde criança, desde o 13 anos que eu o acompanho fazendo esse trabalho."

Casado com sua prima, Kim, aos 40 anos, toma conta de um pequeno espaço cultural que tenta manter viva a memória de Mestre Dezinho, através de recortes de jornais e revistas, certificados de prêmios, diplomas de reconhecimento, fotos, ferramentas pessoais que ele utilizou e alguns artefatos esculpidos pelo Mestre. Enquanto mantém aberto ao público o memorial, Kim aproveita parte do espaço mais ao fundo como oficina para esculpir suas próprias peças. Lá, podemos encontrá-lo concentrado em meio a toras de madeira, utilizando ferramentas antigas, que foram de Mestre Dezinho por quase 50 anos, para a elas dar formas religiosas. Hoje, Kim e os outros aprendizes diretos de Mestre Dezinho são bastante procurados pelo trabalho que realizam com a madeira, por isso muitas vezes lhes é atribuído o status de mestres.

Embora a figura de Mestre Dezinho se constitua em ícone exemplo a seguir no que se refere às obras dos santeiros piauienses, uma das principais características desse grupo é a nítida distinção das formas das peças de cada artesão/artista. Não é necessário ser especialista em arte para, com olhar um pouco mais atento, identificar o "estilo" 
dos traços de cada santeiro. A habilidade que desenvolveram a partir da transmissão das técnicas corretas para o corte da madeira, o conhecimento de soluções para o material e o uso adequado de cada ferramenta foi a base para que cada um formulasse seu próprio estilo de expressar a arte - olhos mais ou menos arregalados, pés maiores ou menores, entalhes mais grossos ou mais finos...

\section{O OFÍCIO E OS MODOS DE FAZER DA ARTE SANTEIRA PIAUIENSE}

O ofício e os modos de fazer funcionam cotidianamente pela manipulação de material proveniente do meio natural - a madeira. O processo de produção começa pela compra preferencialmente do cedro originário das florestas do Estado do Pará. Ao adquirir a madeira por preço considerado elevado, os santeiros, partindo das diferentes demandas que determinam a forma e o tamanho, procuram o tronco de madeira que julgam ser mais adequado para o tipo de trabalho a ser realizado.

Os primeiros cortes no tronco são realizados com ferramentas mais pesadas, como enxó e serrote, obedecendo às proporções previamente estabelecidas na madeira para o local da cabeça, do tronco, dos braços, saia, pés ou base. Após a definição dessas partes, é a vez das ferramentas para cortes mais leves, como o formão, que recebe pancadas de um porrete ou das próprias mãos para desbastar a peça. Nessa etapa, os cortes são realizados percorrendo toda a madeira para garantir proporção harmônica do corpo. O santeiro está sempre em constante alerta para evitar tirar pedaços de madeira que comprometam a evolução da peça. Se isso ocorre, entretanto, as soluções são imediatas - incluindo mudar a forma da peça - para não perder a madeira, muito cara, por completo.

As etapas seguintes demandam utilização de ferramentas de medição, como a graminha, muito utilizada na marcenaria, com que o santeiro marca a altura da base e a abertura dos pés. Para a abertura dos pés, ele tanto pode utilizar o formão e o porrete, o que lhe toma bastante tempo, ou, em alguns casos, a furadeira elétrica.

Iniciando a fase de acabamento, já com as partes do corpo definidas pelos cortes das ferramentas anteriores, o santeiro utiliza o lápis para desenhar na peça olhos, nariz, boca, orelhas, cabelos, mãos, pés calçados ou não, dedos, além da indumentária e seus detalhes temáticos, entre outros. Essas partes vão sendo cortadas com alternância de formões de todos os tamanhos, a faca amolada e pontiaguda, e um compasso para adequar proporções. Para fixar a peça enquanto realiza esses cortes e impedir seu movimento, o santeiro a prende com um grampo à mesa de trabalho.

A conclusão da escultura se dá com a utilização de um espoque (ou poquecher) ou qualquer outro objeto que, com lâmina, vá raspando e arredondando seus contornos. Em seguida, lixas de diferentes espessuras vão 'amaciando' a textura até deixá-la pronta para receber a proteção final, que é preparada com matéria-prima bastante abundante na região: a cera de carnaúba. Segundo os santeiros, a opção por essa substância decorre 
do fato de ela nutrir a madeira e não a queimar, como faz o verniz. Após a cera, a escultura é lustrada para puxar o brilho.

Geralmente a etapa do lixamento até a lustração é responsabilidade dos ajudantes dos mestres ou aprendizes, por ser trabalho que toma muito tempo, além de causar dores e ferimentos nos dedos e nas mãos, mesmo quando se utiliza proteção (como fita adesiva ou esparadrapo) - marcam-se, assim, a hierarquia e a transmissão do saber.

A comercialização da peça pode ocorrer por aquisição direta do usuário por encomenda ao santeiro ou por intermédio da Cooperativa de Artesanato Mestre Dezinho Camede ou de atravessadores que compram as peças dos santeiros por preço bem mais baixo do que aquele pelo qual as revende - apesar de esse tipo de transação ser bastante condenado pelos santeiros, muitos a ele se submetem em função da precariedade de suas condições financeiras.

\section{CONCLUSÃO}

A produção da arte santeira do Piauí compreende universo cultural que demarca campo de ação plural devido a seu inestimável valor etnográfico. São construções simbólicas que conduzem a experiências e vivências do homem consigo mesmo, com o outro e com a sociedade no mundo contemporâneo.

A pesquisa ponderou ser decisivo considerar as referências culturais - Igreja Nossa Senhora de Lourdes e Mestre Dezinho - "ícones perfeitos" da arte santeira piauiense, sem deixar de considerar todo o processo complexo de sua constituição. A partir daí, foi possível estabelecer cenário cultural que revelasse determinado modo de vida, escoIhido por pessoas que se dedicam ao ofício de expressar e manifestar artisticamente figuras que são marcas da religiosidade do povo. Essa manifestação cultural mescla elementos que parecem traduzir a imagem do sertanejo nordestino com sua devoção incondicional às divindades.

A construção do ofício de santeiro e os modos de fazer da arte santeira piauiense desvendam seu mundo de forma surpreendente, correspondendo ao domínio de técnicas, coerência temática, criatividade e soluções estéticas personalizadas, originadas do processo de contínua transmissão cultural, tanto do universo simbólico da religiosidade católica quanto das referências culturais contemporâneas, bem como do saber fazer que prescinde de técnicas específicas moldadas ao corpo do artesão/artista.

\section{REFERÊNCIAS BIBLIOGRÁFICAS}

ABREU, R. "Tesouros humanos vivos" ou quando as pessoas transformam-se em patrimônio cultural - notas sobre a experiência francesa de distinção do "Mestre da Arte". In: ABREU, R.; CHAGAS, M. (orgs.). Memória e Patrimônio: ensaios contemporâneos. Rio de Janeiro: DP\&A, 2003.

BRASIL. Constituição da República Federativa do Brasil. São Paulo: Saraiva, 1988.

CAVALCANTI, M. L. Cultura e saber do povo: uma perspectiva antropológica. Revista Tempo Brasileiro, n. 147: 69-78, 2001. 
FISCHER, E. A Função da Arte. In: Sociologia da Arte - I. Rio de Janeiro: Zahar, 1967.

FONSECA, M. C. L. O Patrimônio em Processo: trajetória da política federal de preservação no Brasil. Rio de Janeiro/Brasília: Editora UFRJ/ MinC - Iphan, 2005.

FOUCAULT, M. A Arqueologia do Saber. Rio de Janeiro: Forense Universitária, 1995.

GEERTZ, C. A Interpretação das Culturas. Rio de Janeiro: Guanabara Koogan, 1989.

. O Saber Local: novos ensaios em antropologia interpretativa. Petrópolis: Vozes, 2003.

GIFFONI, M. A. C. Ex-votos, promessas ou milagres. In: Revista do Arquivo Municipal, 193, 43, 1980.

GIRÃO, C. Arte e Patrimônio. In: Iphan. Revista do Patrimônio, 29, 2001.

GONÇALVES, J. R. S. O patrimônio como categoria de pensamento. In: Abreu, R.; Chagas, M. (orgs.). Memória e patrimônio: ensaios contemporâneos. Rio de Janeiro: DP\&A, 2003.

LODY, R. \& SOUZA, M. M. Artesanato Brasileiro; madeira. Rio de Janeiro: Funarte/Instituto Nacional de Folclore, 1988.

MAUSS, M. As técnicas corporais. In: Sociologia e Antropologia. São Paulo: Edusp, 1974.

MESQUITA, A. M. V. Santeiros do Piauí (mimeo. documento do Iphan-PI). 1980.

MACHADO, R. Por Uma Genealogia do Poder. In: Foucault, M. Microfísica do Poder. Rio de Janeiro: Graal, 1999.

SANT'ANA, M. A Face Imaterial do Patrimônio Cultural: os novos instrumentos de reconhecimento e valorização. In: ABREU, R.; CHAGAS, M. (orgs.). Memória e patrimônio: ensaios contemporâneos. Rio de Janeiro: DP\&A, 2003.

SILVA, A. C. Mestre Dezinho de Valença do Piauí. Teresina: Fundação Cultural Monsenhor Chaves, 1998.

STROZENBERG, I. (org.). De corpo e alma. Rio de Janeiro: Comunicação Contemporânea, 1986.

UNESCO. Material de divulgação do sistema de tesouros humanos vivos, 142 a reunião do conselho executivo. Paris, 1993. Mimeo.

VASQUES, C. M. M. Solicitação de Registro do Bem Cultural Cachoeira de lauaretê - Lugar Sagrado dos Povos Indígenas dos rios Uaupés e Papuri, como Patrimônio Cultural Brasileiro. In: Parecer n. 002/2006, Processo n. 01450.010743/2005-75. Brasília, 2006.

Daniel Oliveira da Silva é graduado em ciências sociais e mestrando em antropologia e arqueologia na Universidade Federal do Piauí.

Fabiano Gontijo é doutor e mestre em antropologia pela École des Hautes Études en Sciences Sociales, graduado em sociologia pela Université de Provence - Aix-Marseille I, professor do Departamento de Ciências Sociais da Universidade Federal do Piauí e bolsista de Produtividade em Pesquisa do CNPq. 